\title{
Comprender y defender ( 0 atacar) en la Historia
}

El problema que aquí se trata puede ser planteado, de breve maneIa, en la interrogación siguiente: ies posible hacer historia, objetivamente válida, defendiendo (o atacando) lo que predominantemente ha de escudriñarse en actitud crítica?.

Mirando y remirando el suceder de los acontecimientos, las andanzas, venturas y desventuras de los hombres que merecen el recuerdo de la posteridad, de inmediato una pasión forastera, diferente a las otras, apodérase del sujeto que observa con empecinada atención la existencia de sus congéneres: Emerge rediviva una suerte de vida, al parecer totalmente desaparecida y que moraba en la región de lo olvidado, para seducimos o para enardecernos. Diríase entonces que el hombre del presente retrocede al pasadóghácesecsial abènterycomparte aquellos destinos arcaicos. Es como si espiritualmente no existiesen distancias temporales entre esa vida que se levanta y ese hombre que la observa, adoptando una tan inédita posición. Y así colocado, parece como si debiera banderizarse con las diferentes situaciones pasadas y con las modalidades de esos hombres, sin permitírsele otras actitudes, so pena de invectivas tremendas. $Y$ ya hipotéticamente parcializado, si alguien defendiese o atacase lo que es objeto de su adhesión o de su repulsa, sólo cabría la loa o la imprecación. Lo demás sería superfluo e indigno de

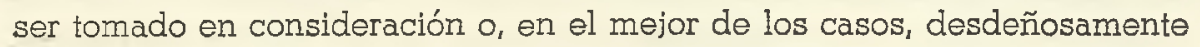
indiferente. Hasta aquí, las repercusiones anímicas de un hombre en actitud cotidiana, en la característica actitud del pre-historiar.

$$
\text { - II - }
$$

Pero ¿qué hacer cuando no sea bastante el revivir ingenuo y meramente sicológico del acontecer histórico? ¿cuándo un intenso afán de co- 
nocer exije su sitial en nuestro espíritu? ¿cuándo más allá de un epidérmico revivir lo histórico, se esté frente al imperativo inherente a todo auténtico historiar: urgar cognoscitivamente en la entraña misma de aquella vida pasada, que en un primer momento conmovíamos de manera sencilla?.

Este es ya un problema distinto, bajo cuyo impulso el sujeto logra remontar aquella ingenua repercusión epidérmica, tan cara al sicologismo histórico, y enfrentarse con las dificultades que plantea el conocimiento histórico. Es, por excelencia, el gran problema del historiador. Y aquí la faena se torna difícil, porque no se trata de que la tendencia cognoscitiva estrangule la intuición irracional de ese vivir histórico, sino que ésta encuentre su complemento en aquélla, y sea posible contemplar la que acaeció y no lo que se desea que hubiera acaecido. Veamos un caso de la historia del Perú.

Cuando José Gabriel Túpac Amaru se levanta, apresando al corregidor Arriaga el cuatro de noviembre de 1780, quien defienda o ataque su movimiento ¿podrá llegar a descubrir lo esencial de aquel aconteclmiento histórico y de aquella vígorosa individualidad? Quizá podríase acompañarla en su vacilante derrotero ${ }_{\text {i }}$ sentir algo de su esperanza o de su angustia, y nada más.

¿Qué es necesario efectuar si se desea no quedar anegado en el flujo viviente de lo acaecido? ¿si se quiere provocar un reflujo y hacer historia?. Es necesariol penetrar en un terreno nuevo, donde la vida histórica ni domine niresté diseçada, 'sino simplemente puesta a distancia tal que adquiera una normal perspectiva para su enjuiciamiento crítico. Porque se defiende o se ataca lo que está indisolublemente unido al observador cotidiano, aquello donde la ausencia de separación impide describir, comprender e interpretar en actitud contemplativa. Es necesario vivir con lo histórico como momento previo para conocerlo, es decir, para ensalzarlo en su aspecto positivo y para censurarlo en su aspecto negativo. Este es un axioma de todo historiador en actitud científica. Cuando se vive el acaecer histórico, existe un avasallador señorío del defender o del atacar; cuando se trata de conocer la vida humana, de historiar, es necesario el comprender para explicar la finalidad de lo acaecido.

$$
- \text { III - }
$$

Mediante el comprender adquieren los acontecimientos un sentido; mediante el defender (o el atacar) desembocan, por el contrario, al extraño territorio del sin-sentido. Este debe ser esquivado, aquél debe ser 
recalcado. Cuando esto no sucede, aparece el falso conocimiento histórico, disquisición epidérmica, galimatías adornado con las galas de la gramática y de una aparente coherencia lógica, en función del no-antropológico principio de causalidad. Aquí aparece, con gran claridad, la típica oposición genérica entre el grupo de las ciencias antropológicas y el de las ciencias naturales. Mientras en éstas lo que tiene principal importancia es la explicación causal, en aquéllas lo que tiene primerísima importancia es la explicación teleológica. Y no es que la causalidad debe ser eliminada en absoluto del conocimiento histórico, sino que debe estar disminuida, subordinada, cabe decir, debe abandonar su rango de principio y convertirse en mero recurso metodológico e ir a la zaga del principio teleológico, que tiene vigencia omnímoda en el terreno de la historia y permite tratar el material antropológico según sus particulares e intransferibles caracteres.

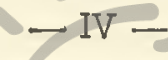

Cuando el principio teleológico no guía la indagación histórica, los resultados obtenidos carecen de validez. Porque como principio (según se ha dicho con anterioridad) la causalidad vale solo para la ciencias naturales; mientras como dispositivo metodológico al servicio de las ciencias antropológicas, ayuda a la seriación cronológica de los acontecimientos y de las partes que lo conforman, es decir a la realización de lo ne cesario e insuficiente a todo normal historiar. De donde se infiere, que ubicar los acontecimientose enuelctiempo Golen elsespacio es tarea preparatoria para una más íntima penentración que conduzca a comprender lo acaecido y, por ende, a descubrir su recóndita finalidad. Narrar no es hacer historia sino historiografía, cumplir con el imprescindible tramo inicial. La historia es la resultante de la historiografía o parte narrativa, y de la historiología o parte interpretativa. Pudiéndose parafrasear, que toda historiografía sin una historiología es ciega y toda historiología sin una historiografía es vacía. La auténtica historia vive de la permanente e indiscutible correlación de ambas. Por eso, cuando se describe, por ejemplo, la rebelión del cacique Túpac Amaru y se pone en una escrupulosa ubicación cronológica los diversos momentos que la conforman, al término de tan sacrificada tarea ¿no queda aun en el espíritu una latente pero avasalladora insatisfacción? ¿podríase narrar solamente y poner de lado la interpretación correspondiente?.

De manera apodíctica, la narración clásica aparece como una acción característicamente trunca. Es la contestación de quienes entienden his- 
toriográfía iqual historia, de quienes toman la parte por el todo. Describir conduce a interpretar, Assimismo, interpretar supone la mostración previa de lo acaecido, so pena de caer en arbitrarias divagaciones. Ahora bien, puede argumentarse que el atraso eurístico-historiográfico lleva en países como el nuestro, a una prudente restricción de las interpretaciones. Pero, restringir no es eliminar; sólo significa que los resultados interpretativos son provisionales, modificándose según lo exija la presencia de materiales novísimos o de revisiones fundamentales en el material ya trabajado. De este modo, en el ejemplo citado de la rebelión del cacique Túpac Amaru, dada su descripción (historiografía) pásase a su interpretación (historiologia), pasos previos que permiten ingresar en su respectivo conocimiento histórico y estar capacitados para una revisión crítica.

Por otra parte, la experiencia enseña cómo el historiador únicamente siente una espiritual satisfacción específica cuando interpreta (aunque sólo sea en forma provisional), pues considera este momento como término y coronamiento de su tarea, elíminando la trágica insatisfacción de contemplar el aspecto externo del acontecimiento e ignorar su sentido. Tâl situación espiritual es más que una mera repercusión sicológica; más bien aparece en estrecha vinculación con una exigencia teorética, vigente tanto para las ciencias antropológicas cuanto para las no-antropológicas. Además, es aquí donde lo dicho anteriormente debe recalcarse: la complementaria revisión idelascdiversas intérpretaciones acerca de un acontecimiento (por ejemplo, el de Túpac Amaru) mediante el reenfoque crítico de sus más antagonicas interpretaciones.

Si en lugar de la actitud de comprender se adoptase la de defender (o atécar) no se llegaría a desentrañar la finalidad yacente en los acontecimientos, abriéndose, en realidad, una simple válvula de escape a oscuros impulsos, no canalizados, característicos de una actitud que pertenece a la ingenua etapa del pre-historiar.

$$
+\mathrm{V}-
$$

¿Se habrá avanzado lo suficiente en la planteada oposición entre comprender y defender (o atacar) en la historia?. Aunque el defender (o atacar) moran en un común territorio, con relación al comprender existen sendas conexiones. En consecuencia, aparece como distintos, por una parte, el comprender-defender $y$; por otra, el comprender-atacar.

Cuando se trata de comprender partiendo de un acontecimiento que se defiende, la dirección intencional emana de un espíritu en actitud po- 
sitiva, de una persona que simpatiza con posibles rectificaciones, es decir, se está más acá de la terquedad y en una fácil actividad espiritual. La superación del estadio del defender y su ingreso a territorios del comprender cae bajo el signo positivo de valor. En cambio, cuando se trata de superar el estadio del atacar y penetrar en la esfera del comprender, la progresión cae bajo el signo negativo de valor; también se está más acá de la terquedad, pero en una actividad de difícil cumplimiento. Así frente al episodio de la entrega del cacique Túpac Amaru en manos de las autoridades españolas, al pasar por el pueblo de Langui, la reacción inmediata es condenar de manera absoluta aquella desdichada acción. Sin embargo, a pesar de la repulsión vigorosa que el hecho suscita, el historiador efectúa el esfuerzo de comprender, asimismo, dicha acción y.desentrañar su sentido. Si esto último no fuera posible al historiador, sería necesario negar la posibilidad del enfoque cognoscitivo de las acciones negativas acaecidas en todo tiempo y su valoración correspondiente. Pero, que esto es posible está probado por el hecho de que dicha valoración de lo negativo en la historia ha sido, es y seguirá siendo realizado. Como se ve, del defender y del atacar danse pues sendos saltos hacia el nuevo ycomún terreno de lo comprensión histórica.

Por último, más allá del trabajo histórico en sentido estricto, cerniéndose en horizontes de mayor altura, una integral visión de lo antropológico, una culturologíał cumple su nêcesāriotpapel regulativo para la auténtica comprensión histórica. Y así la Historia (ciencia cuyos objetos son los acontecimiénfosf por su inetable pretension de integralidad y de interpretar cada acontecimiento en función de estructuras más amplias, logra extender una mayor claridad y una necesaria valoración de sus propios objetos (en función del comprender) superando la etapa ingenua del defender (o atacar), que cuando predomina invalida muchos esfuerzos meritorios.

Daniel Valcárcel. 